\title{
Unexpected longevity in patients with severe kyphoscoliosis
}

\author{
WILLIAM N. ROM ${ }^{1}$ AND ALBERT MILLER ${ }^{2}$
}

From the Division of Pulmonary Diseases, Department of Medicine, the Environmental Sciences Laboratory, Department of Community Medicine, Mount Sinai School of Medicine of the City University of New York, and Mount Sinai Services-City Hospital Center at Elmhurst, New York, USA

Rom, W. N., and Miller, A. (1978). Thorax, 33, 106-110. Unexpected longevity in patients with severe kyphoscoliosis. The threat of premature death in the fourth or fifth decades of life from cardiorespiratory failure in kyphoscoliosis is well known. Ten patients with severe kyphoscoliosis (curves greater than $100^{\circ}$ ), who had survived into their seventh decade free of cardiorespiratory failure, were encountered over a four-year period. Pulmonary function studies on five patients showed impaired chest bellows function. Four patients died of acute respiratory failure at ages $65,73,79$, and 85 . These patients illustrate that severe deformity is not incompatible with a long and active life.

Since the time of Hippocrates patients with severe kyphoscoliosis have been known to be liable to premature death from cardiorespiratory failure. The severity of the physiological impairment was characterised by Bergofsky et al. (1959) and is related to the degree of spinal curvature. Premature death occurs in patients with severe deformity. Symptoms and signs of cardiorespiratory failure often appear during the fourth or fifth decades of life. The course is rapidly progressive once failure becomes manifest (Fraser and Paré, 1970). We were therefore impressed when we encountered 10 patients over a four-year interval with 'severe kyphoscoliosis who had survived into the seventh decade without clinically significânt cardiorespiratory embarrassment.

\section{Methods}

Spinal curvature was quantitated by the method of Bergofsky et al. (1959). All 10 patients had a major curvature greater than $100^{\circ}$. Pulmonary function tests were done using a water spirometer and either helium-dilution or body plethysmography to determine functional residual capacity

${ }^{1}$ Supported in part by an American Lung Association Fellowship and National Institute of Environmental Health Sciences Center Grant ES-00928

'Supported in part by the Jack Martin Fund
(FRC) and total lung capacity (TLC). Predictedo

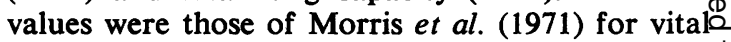
capacity (VC), forced expiratory volume in one $\overrightarrow{\overrightarrow{0}}$ second $\left(F E V_{1}\right)$, and forced expiratory flow 3 $\left(\mathrm{FEF}_{25-75}\right)$, of Baldwin et al. (1948) for maxima㞔 voluntary ventilation (MVV), and of Bates et al: (1971) for total lung capacity (TLC). Values were predicted using arm span rather than heighe (Hepper et al., 1965).

\section{Case summaries}

CASE 1

A 60-year-old man with kyphoscoliosis since child은 hood had been treated at that time with a body cast for two years. He worked as a timekeeper on: construction projects. When seen in 1975, he hado had progressive dyspnoea on exertion and produc=tive cough for the past two years, although he had never smoked. He had a respiratory rate of 30 pexw minute, a marked gibbus of the thoracic spine and normal breath sounds (spinal curve $115^{\circ}$ ).

\section{CASE 2}

A 62-year-old woman had kyphoscoliosis dating from poliomyelitis at the age of 3 years. She wao placed in a body cast at age 12 for six months? She is a 45 pack/year smoker with morning cougl $\mathbb{B}$ but has experienced no dyspnoea. When examined 
in 1975 , she had a respiratory rate of 18 per minute and clear lungs (spinal curve $105^{\circ}$ ).

\section{CASE 3}

A 66-year-old non-smoking woman had kyphoscoliosis dating back to childhood. Her medical history includes diabetes, an old myocardial infarction, mild cardiac failure, and oesophagitis. When examined in 1975, she was tachypnoeic but had clear lungs on auscultation (spinal curve $\left.135^{\circ}\right)$.

\section{CASE 4}

A 72-year-old woman had had kyphoscoliosis since poliomyelitis at the age of 5 years. In the year before admission she had developed bronchitis with progressive dyspnoea. Pulmonary function studies (Table) showed airways obstruction as well as a marked decrease in VC. She was an exsmoker, having smoked one pack per day for at least two years, stopping 20 years previously. She was admitted to hospital in September 1975 in respiratory failure. She was intubated and ventilated but died in November 1975 (spinal curve $105^{\circ}$ ).

\section{CASE 5}

A 65-year-old non-smoking office worker had developed kyphoscoliosis after poliomyelitis in early childhood. She had remained in good health with no hospitalisations despite several episodes of pneumonia. Over the past year she began to complain of dyspnoea on exertion, now present on walking less than one block, but has continued to work. On examination she was alert with a respiratory rate of 20 per minute and crackles at the left base (spinal curve $105^{\circ}$ ).

\section{CASE 6}

An 85-year-old woman, with kyphoscoliosis since childhood, had developed congestive heart failure during the last year of life. In 1973, at age 83, she survived her first episode of acute respiratory failure, precipitated by influenza, and was discharged from hospital in less than one week. In
September 1975, she was admitted to hospital in acute respiratory failure due to bronchopneumonia. Despite appropriate therapy she died (spinal curve $135^{\circ}$ ).

\section{CASE 7}

A 65-year-old woman had had kyphoscoliosis since childhood. She had managed without difficulty or medication until she developed acute shortness of breath and was admitted to hospital in acute respiratory failure during 1974 . She was treated with intubation and supported ventilation but died suddenly from a pulmonary embolus (spinal curve $110^{\circ}$ ).

\section{CASE 8}

A 65-year-old woman with kyphoscoliosis developed dyspnoea on exertion which responded to diuretic therapy. When seen in spring 1976 she had a respiratory rate of 20 per minute and a grade III/IV diastolic decrescendo murmur (spinal curve $130^{\circ}$ ).

\section{CASE 9}

A 73-year-old non-smoking retired pharmacist had a past history of poliomyelitis and a spinal fusion at age 33. In 1973 he fractured the left hip and underwent a surgical repair. He subsequently experienced mild dyspnoea and was treated with spironolactone (Aldactone). He was admitted to hospital in February 1976 for evaluation of Jacksonian seizures but suffered a respiratory arrest during his first night and required intubation. He survived a complicated course, including tracheostomy with supported ventilation (spinal curve $135^{\circ}$ ).

\section{CASE 10}

A 79-year-old retired lawyer had had idiopathic scoliosis since childhood. He was a non-smoker and had no history of congestive heart failure. In 1971 he underwent a suprapubic prostatectomy. He lived alone and was able to care for himself. He was admitted to hospital in May 1977 with fever, cough, and haemoptysis. He had a respira-

Table Pulmonary function tests (obtained when patients were stable and ambulatory)

\begin{tabular}{|c|c|c|c|c|c|c|c|c|c|c|c|}
\hline Patient & Age & $\begin{array}{l}V C \\
(m l)\end{array}$ & $\begin{array}{l}M V V \\
(l / \min )\end{array}$ & $\begin{array}{l}F E V_{1} / \\
F V C \times 100\end{array}$ & $\begin{array}{l}F E F_{25-75} \\
(l / s e c)\end{array}$ & $\begin{array}{l}F R C \\
(l)\end{array}$ & $\begin{array}{l}T L C \\
(l)\end{array}$ & $R V / T L C$ & $\begin{array}{l}\mathrm{PaO}_{2} \\
\left(\mathrm{mmHg} \mathrm{H}_{\mathrm{g}}\right.\end{array}$ & $\begin{array}{l}\mathrm{PaCO}_{2} \\
\left(\mathrm{~mm} \mathrm{Hg}_{\mathrm{g}}\right)\end{array}$ & $p H$ \\
\hline $\begin{array}{l}1 \\
2 \\
3 \\
4 \\
8\end{array}$ & $\begin{array}{l}60 \\
62 \\
66 \\
72 \\
65\end{array}$ & $\begin{array}{r}920(22) \\
2020(67) \\
840(36) \\
570(24) \\
1170(36)\end{array}$ & $\begin{array}{ll}33 & (31) \\
72 & (122) \\
56 & (44) \\
19 & (33) \\
43 & (74)\end{array}$ & $\begin{array}{l}63 \\
70 \\
63 \\
54 \\
66\end{array}$ & $\begin{array}{l}1 \cdot 16(39) \\
1.42(56) \\
0.16(7) \\
0.65(25)\end{array}$ & $\begin{array}{l}0 \cdot 77 \\
2 \cdot 31 \\
1 \cdot 95\end{array}$ & $\begin{array}{l}1 \cdot 77(26) \\
2 \cdot 81(70) \\
2.86(55)\end{array}$ & $\begin{array}{l}48 \% \\
70 \% \\
55 \%\end{array}$ & $\begin{array}{l}59 \\
74 \\
77 \\
59 \\
72\end{array}$ & $\begin{array}{l}57 \\
41 \\
39 \\
42 \\
37\end{array}$ & $\begin{array}{l}7 \cdot 36 \\
7 \cdot 37 \\
7 \cdot 41 \\
7 \cdot 41 \\
7 \cdot 45\end{array}$ \\
\hline
\end{tabular}

Per cent predicted in parentheses. 
tory rate of 28 , a marked gibbus, decreased breath sounds in the right posterior chest, and peripheral cyanosis. On room air initial arterial $\mathrm{pH}$ was $7 \cdot 38$, $\mathrm{Po}_{2} 58 \mathrm{mmHg}$, and $\mathrm{PCO}_{2} 33 \mathrm{mmHg}$. $\mathrm{He}$ was treated for pneumonia but suddenly developed respiratory failure with progressive hypercapnia and cardiac arrhythmias, and died suddenly (spinal curve $115^{\circ}$ ).

\section{Results}

The mean age of the group was $69 \cdot 3$ years. The mean spinal curvature was $119^{\circ}$.

The results of pulmonary function studies obtained in five patients are shown in the Table. Four of the five patients had a severe restrictive impairment and slight to severe reduction in MVV. The remaining patient had a moderate decrease in VC with a normal MVV. In the three patients $(1,3$, and 8$)$ in whom they were measured functional residual capacity, residual volume, and total lung capacity were markedly reduced, although the ratio of RV to TLC was increased. When studied as stable outpatients, two of the five patients ( 1 and 4 ) had arterial hypoxaemia; patient 1 had compensated respiratory acidosis. Values for $\mathrm{PaCO}_{2}$ were normal in the other four patients. In only one patient were flow rates reduced disproportionately to the reduction in $\mathrm{VC}$, indicating airway obstruction (patient 4 , in which $\mathrm{FEV}_{1} / \mathrm{FVC}$ was $54 \%$ ).

Four patients died of acute respiratory failure precipitated by bronchopulmonary infection. Two patients ( 4 and 6$)$ had not been symptomatic until one to two years before the fatal episode. The other two patients ( 7 and 10$)$ were asymptomatic until acute respiratory failure supervened at the ages of 65 and 74, respectively. None of the four deceased patients was submitted to necropsy.

Of the six surviving patients, five had dyspnoea and were treated for cardiac failure. In one of these, the failure was attributed to myocardial infarction. The earliest age at which dyspnoea appeared was 58. The remaining patient is asymptomatic. Five of the six survivors have remained active; of these, two are gainfully employed.

\section{Discussion}

The mechanisms for respiratory impairment in kyphoscoliosis are well understood. Chest wall restriction results in a decreased VC, TLC, and tidal volume (Caro et al., 1960). Flow rates are reduced in proportion to the reduction in vital capacity (Caro and DuBois, 1961). A correlation between the severity of spinal curvature and im paired respiratory function has been established; respiratory impairment is generally not manifestem

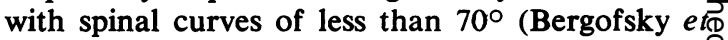
al., 1959; Makley et al., 1968; Zorab, 1973a). With greater deformity, ventilation-perfusion im-s balance leads to hypoxaemia (Dollery et al. $\overrightarrow{\mathrm{O}}$ 1965; Shannon et al., 1970, 1971); Bjure and Nachemson, 1973). Hypoxaemia results in active pulmonary vasoconstriction that has been demon $\frac{\overrightarrow{ }}{\overrightarrow{2}}$ strated by a shortened pulmonary artery to capilix lary flow conduction time (Littler et al., 1973) Hypercapnia secondary to alveolar hypoventilation supervenes in the later stages. Cardiac failure may follow with a progressively downhill course leading to premature death (Fisher and Dolehide, 1954, Hanley et al., 1958; Abrahamson, 1959). Post mortem the media of the small pulmonary arterioles is thickened, and right ventriculare hypertrophy is present (Naeye, 1961). Davies an Reid (1971) described a decrease in the number of alveoli, atrophy of pulmonary parenchyma, and a decreased number as well as thickening of pul ${ }^{\infty}$ monary arterioles in patients with idiopathic kyphoscoliosis. All four patients reported by them died before the age of 18; two showed righ 5 ventricular hypertrophy and died before the ags. of 15 .

In the current series, 10 patients with severe kyphoscoliosis (curves greater than $100^{\circ}$ ), wh\$ survived into the seventh decade without cardio respiratory failure, were encountered in a foure year interval in two large metropolitan hospitals Prolonged survival and freedom from cardioe respiratory failure in patients with severe kyphoscoliosis has not been emphasised. In a series of 27 patients with kyphoscoliosis studied by Bergofsky et al. (1959) only eight were 60 or more years old. Seven of these had clinical cor pul monale. The age when cardiac failure began was not stated. Bruderman and Stein (1961) described four patients over 60 years of age with kyphog. scoliosis. Only one had a spinal curve greater than $100^{\circ}$; this patient had cardiorespiratory failure? Shaw and Read (1960) reported two patients ovef 60 years of age, one of whom had cardiorespirat tory failure. The degree of curvature was not stated. Most reports concerning pulmonary funco tion in kyphoscoliosis are confined to younge patients (Caro and DuBois, 1961; Makley et al 1968; Shannon et al., 1970; Kafer, 1974).

In all of the present patients the primary curve was thoracic. The effect of the curve was exacero bated by vertebral rotation, both contributing to the deformity in the chest cage. Longevity has been noted in Pott's disease. This is probably due 
to the greater kyphosis than scoliosis allowing more adequate ventilation of the lungs by the diaphragm and normal gas transfer. Paralytic scoliosis (for example, secondary to poliomyelitis) may result in severe impairment at an early age owing to weakness of the respiratory muscles. This may be detected by a greater reduction in maximum voluntary ventilation (Zorab, 1973a).

Zorab has followed 629 patients with scoliosis since 1962; the age distribution was not given. Of these, 33 have died, those in 'middle age' generally from cardiac insufficiency and those in the younger age group from acute respiratory infection (Zorab, 1973b). One hundred and two children with idiopathic scoliosis (excluding paralytic scoliosis, for example, poliomyelitis, etc) noted during the period 1913-18 in Sweden were followed up to 1963 (Nilsonne and Lundgren, 1968). There were 46 deaths, which was $2 \cdot 2$ times the expected rate. Sixty per cent of the deaths were due to cardiopulmonary disease and $47 \%$ of those alive were prematurely disabled and unable to work. Another follow-up of 117 patients in Scandinavia revealed twice the expected mortality, $30 \%$ receiving disability compensation, and none of those working able to perform manual labour (Nachemson, 1968). The severity of spinal curvature was not recorded in either report. Deaths were predominantly in the fourth and fifth decades of life. A death rate similar to the normal was found in 215 middle-aged scoliotic patients seen initially as adolescents from 1932 to 1948 and followed to 1968 (Collis and Ponseti, 1969). Two of 17 deaths occurred in subjects with thoracic curves greater than $100^{\circ}$ at ages 36 and 72 . Sixteen per cent of those with thoracic radiographs (134) had a primary curve greater than $100^{\circ}$. Those with thoracic curves greater than $60^{\circ}$ were more likely to develop severe deformity by middle age and to have diminished vital capacities.

Patients with severe kyphoscoliosis are vulnerable to acute respiratory failure generally brought on by infection. This was the cause of death in the four fatalities in this series. These patients had not had symptoms until one to two years before the fatal episode.

\section{References}

Abrahamson, M. L. (1959). Pulmono-cardiac failure associated with deformity of the chest. Lancet, 1 , 449-450.

Baldwin, E., Cournand, A., and Richards, D. W. (1948). Pulmonary insufficiency I. Physiological classification, clinical methods of analysis, standard values in normal subjects. Medicine, 27, 243-278.
Bates, D. V., Macklem, P. T., and Christie, R. V. (1971). Respiratory Function in Disease. W. B. Saunders, Philadelphia.

Bergofsky, E. H., Turino, G. M., and Fishman, A. P. (1959). Cardiorespiratory failure in kyphoscoliosis. Medicine, 38, 263-317.

Bjure, J., and Nachemson, A. (1973). Non-treated scoliosis. Clinical Orthopedics and Related Research, 93, 44-52.

Bruderman, J., and Stein, M. (1961). Physiologic evaluation and treatment of kyphoscoliotic patients. Annals of Internal Medicine, 55, 94-102.

Caro, C. G., Butler, J., and Dubois, A. B. (1960). Some effects of restriction of chest expansion on pulmonary function in man: An experimental study. Journal of Clinical Investigation, 39, 573583.

Collis, D. K., and Ponseti, I. V. (1969). Long-term follow-up of patients with idiopathic scoliosis not treated surgically. Journal of Bone and Joint Surgery, 51 A, 425-445.

Davies, J., and Reid, L. (1971). Effects of scoliosis on growth of alveoli and pulmonary arteries and right ventricle. Archives of Disease in Childhood, 46, 623-632.

Dollery, C. T., Gillam, P. M. S., Hugh-Jones, P., and Zorab, P. A. (1965). Regional lung function in kyphoscoliosis. Thorax, 20, 175-181.

Fisher, J. W., and Dolehide, R. H. (1954). Fatal cardiac failure in persons with thoracic deformities. Archives of Internal Medicine, 93, 687-697.

Fraser, R. B., and Paré, J. A. P. (1970). Diagnosis of Diseases of the Chest, pp. 1243-1245. W. B. Saunclers, Philadelphia.

Hanley, T., Platts, M. M., Clifton, M., and Morris, T. (1958). Heart failure of the hunchback. Quarterly Journal of Medicine, 27, 155-171.

Hepper, N. G., Black, L. F., and Fowler, W. S. (1965). Relationships of lung volume to height and arm span in normal subjects and in patients with spinal deformity. American Review of Respiratory Disease, 91, 356-363.

Kafer, E. R. (1974). Respiratory function in paralytic scoliosis. American Review of Respiratory Disease, $110,450-457$.

Littler, W. A., Reuben, S. R., and Lane, D. J. (1973). Lung blood flow studies in patients with scoliosis and neuromuscular weakness. Thorax, 28, 209 213.

Makley, J. T., Herndon, C. H., Inkley, S., Doershuk, C., Matthews, L., Post, R., and Littell, A. (1968). Pulmonary function in paralytic and non-paralytic scoliosis before and after treatment. Journal of Bone and Joint Surgery, 50A, 1379-1390.

Morris, J. F., Koski, A., and Johnson, V. C. (1971). Spirometric standards for healthy non-smoking aclults. American Review of Respiratory Disease, 103, 57-67.

Nachemson, A. (1968). A long term follow-up study of non-treated scoliosis. Acta Orthopaedica Scandinavica, 39, 466-476. 
Naeye, R. L. (1961). Kyposcoliosis and cor pulmonale. A study of the pulmonary vascular bed. American Journal of Pathology, 38, 561-574.

Nilsonne, U., and Lundgren, K. (1968). Long-term prognosis in idiopathic scoliosis. Acta Orthopaedica Scandinavica, 39, 456-465.

Shannon, D. C., Riseborough, E. J., Valenca, L., and Kazemi, H. (1970). The distribution of abnormal lung function in kyphoscoliosis. Journal of Bone and Joint Surgery, 52A, 131-144.

Shannon, D. C., Riseborough, E. J., and Kazemi, H. (1971). Ventilation perfusion relationships following correction of kyphoscoliosis. Journal of the American Medical Association, 217, 579-584.
Shaw, D. B., and Read, J. (1960). Hypoxia and thoracic scoliosis. British Medical Journal, 2, 14861489.

Zorab, P. A. (1973a). Pulmonary function in spina deformity. Clinical Orthopedics and Related $\mathbb{B}$ Research, 93, 33-37.

Zorab, P. A. (1973b). Proceedings: prognosis for life in childhood scoliosis. Archives of Disease in Child hood, 48, 824-825.

Requests for reprints to: Dr. A. Miller, Division of Pulmonary Diseases, Mount Sinai Hospital, 5th Avenue at 100th Street, New York, NY 10029, USA. 